NASA/CR-2002-211758

ICASE Report No. 2002-25

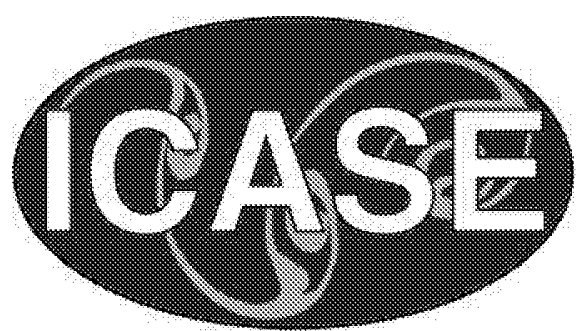

\title{
An Irreversible Constitutive Law for Modeling the Delamination Process Using Interface Elements
}

Vinay K. Goyal and Eric R. Johnson

Virginia Polytechnic Institute and State University, Blacksburg, Virginia

Carlos G. Dávila

NASA Langley Research Center, Hampton, Virginia

Navin Jaunky

ICASE, Hampton, Virginia 


\section{The NASA STI Program Office . . . in Profile}

Since its founding, NASA has been dedicated to the advancement of aeronautics and space science. The NASA Scientific and Technical Information (STI) Program Office plays a key part in helping NASA maintain this important role.

The NASA STI Program Office is operated by Langley Research Center, the lead center for NASA's scientific and technical information. The NASA STI Program Office provides access to the NASA STI Database, the largest collection of aeronautical and space science STI in the world. The Program Office is also NASA's institutional mechanism for disseminating the results of its research and development activities. These results are published by NASA in the NASA STI Report Series, which includes the following report types:

- TECHNICAL PUBLICATION. Reports of completed research or a major significant phase of research that present the results of NASA programs and include extensive data or theoretical analysis. Includes compilations of significant scientific and technical data and information deemed to be of continuing reference value. NASA's counterpart of peer-reviewed formal professional papers, but having less stringent limitations on manuscript length and extent of graphic presentations.

- TECHNICAL MEMORANDUM. Scientific and technical findings that are preliminary or of specialized interest, e.g., quick release reports, working papers, and bibliographies that contain minimal annotation. Does not contain extensive analysis.

- CONTRACTOR REPORT. Scientific and technical findings by NASA-sponsored contractors and grantees.
- CONFERENCE PUBLICATIONS. Collected papers from scientific and technical conferences, symposia, seminars, or other meetings sponsored or cosponsored by NASA.

- SPECIAL PUBLICATION. Scientific, technical, or historical information from NASA programs, projects, and missions, often concerned with subjects having substantial public interest.

- TECHNICAL TRANSLATION. Englishlanguage translations of foreign scientific and technical material pertinent to NASA's mission.

Specialized services that complement the STI Program Office's diverse offerings include creating custom thesauri, building customized data bases, organizing and publishing research results . . . even providing videos.

For more information about the NASA STI Program Office, see the following:

- Access the NASA STI Program Home Page at http://www.sti.nasa.gov

- Email your question via the Internet to help@sti.nasa.gov

- Fax your question to the NASA STI Help Desk at (301) 621-0134

- Telephone the NASA STI Help Desk at (301) 621-0390

- Write to: NASA STI Help Desk NASA Center for AeroSpace Information 7121 Standard Drive Hanover, MD 21076-1320 
NASA/CR-2002-211758

ICASE Report No. 2002-25

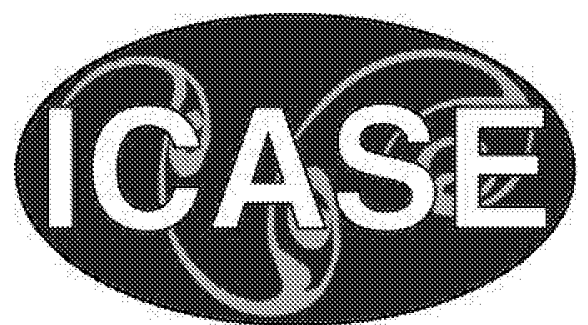

\section{An Irreversible Constitutive Law for Modeling the Delamination Process Using Interface Elements}

Vinay K. Goyal and Eric R. Johnson

Virginia Polytechnic Institute and State University, Blacksburg, Virginia

Carlos G. Dávila

NASA Langley Research Center, Hampton, Virginia

Navin Jaunky

ICASE, Hampton, Virginia

ICASE

NASA Langley Research Center

Hampton, Virginia

Operated by Universities Space Research Association 
Available from the following:

NASA Center for AeroSpace Information (CASI)

7121 Standard Drive

Hanover, MD 21076-1320

(301) 621-0390
National Technical Information Service (NTIS)

5285 Port Royal Road

Springfield, VA 22161-2171

(703) $487-4650$ 


\title{
AN IRREVERSIBLE CONSTITUTIVE LAW FOR MODELING THE DELAMINATION PROCESS USING INTERFACE ELEMENTS
}

\author{
VINAY K. GOYAL*, ERIC R. JOHNSON ${ }^{\dagger}$, CARLOS G. DÁVILA ${ }^{\ddagger}$, AND NAVIN JAUNKY ${ }^{\S}$
}

\begin{abstract}
An irreversible constitutive law is postulated for the formulation of interface elements to predict initiation and progression of delamination in composite structures. An exponential function is used for the constitutive law such that it satisfies a multi-axial stress criterion for the onset of delamination, and satisfies a mixed mode fracture criterion for the progression of delamination. A damage parameter is included to prevent the restoration of the previous cohesive state between the interfacial surfaces. To demonstrate the irreversibility capability of the constitutive law, steady-state crack growth is simulated for quasi-static loading-unloading cycle of various fracture test specimens.
\end{abstract}

Key words. composite structures, progressive failure, ply damage mode, intradamage mode, interlaminar damage mode, delamination, interface elements, decohesion elements, buckling, postbuckling

\section{Subject classification. Structural Mechanics}

1. Introduction. Delamination in composite structures usually originates from geometric discontinuities and material defects such as free edges, dropped plies, re-entrant corners, notches, and transverse matrix cracks. Recently, significant progress has been made in the development of tools to predict intralaminar damage, which often precedes the onset of delamination. Delamination can be a major failure mode in composites structures and can lead to significant loss of structural integrity. Fracture mechanics techniques such as the virtual crack closure technique (VCCT) $[1,2]$ has been successfully used in the prediction of delamination growth. However, an initial delaminated area must be predefined and a self-similar crack growth is assumed.

To overcome the limitations associated with the VCCT, interface elements can be located between composite lamina to simulate initiation of delamination and non-self-similar growth of delamination cracks without specifying an initial crack. Delamination is initiated when the interlaminar traction attains the maximum interfacial strength, and the delamination front is advanced when the local surface fracture energy is consumed. A softening constitutive law that relates tractions to the relative displacements is generally used to formulate interface elements. The softening constitutive law is based on the procedures used by Dugdale[3] and Barenblatt[4] to find the extent of the plastic zone ahead of the crack tip in ductile metals; the size of which is chosen such that the stress singularity from linear elastic fracture mechanics disappears. The softening portion of the constitutive law accounts for the complex mechanisms occurring in the volume of material ahead of the crack tip by which large amounts of energy are absorbed in the fracture process. For laminated composites these mechanisms include nucleation, growth and coalescence of microcavities. Hilleborg[5] developed the first comprehensive interface finite element model and applied this method in

\footnotetext{
* Graduate Research Assistant, Aerospace and Ocean Engineering Department, Virginia Polytechnic Institute and State University, Blacksburg, VA 24061-0203

$\dagger$ Professor, Aerospace and Ocean Engineering Department, Virginia Polytechnic Institute and State University, Blacksburg, VA 24061-0203

¥Aerospace Engineer, Analytical and Computational Methods Branch, NASA Langley Research Center, Hampton, VA 23681-2199

§Senior Staff Scientist, ICASE, NASA Langley Research Center, Hampton, VA 23681-2199. This research work was supported by NASA Langley Research Center under NASA Contract No. NAS1-97046 while in residence at ICASE, NASA Langley Research Center, Hampton, VA 23681-2199.
} 
concrete cracking. Later, Needleman[6] developed a cohesive-decohesive formulation to simulate dynamic crack growth in isotropic elastic solids.

The exact mathematical form of the interfacial constitutive law is less important than its capability to represent the maximum interfacial strength and critical fracture energy. Hence, the functional dependence of the traction field on the displacement jump across the interface is not uniquely defined. However, functions with continuous derivatives have a numerical advantage over functions with discontinuous derivatives when used with Newton-Raphson method because the tangent stiffness is smooth. A smooth tangent stiffness as a function of the relative opening displacement has been found to mitigate the numerical oscillations encountered in using a softening constitutive relation and to eliminate oscillatory convergence difficulties[7].

The exponential function for the softening constitutive law is smooth and mimics the physics involved in the separation of two atoms initially bonded[8]. This form of the constitutive law has been used in the analysis of crack initiation, dynamic growth, branching, and arrest in homogeneous materials[9]. Shahwan and Waas[10] used it to study delamination of composite structures caused by compressive loads. The various exponential constitutive laws that have been successfully employed to simulate delamination are based on the assumption that the consumed local surface fracture energy can be recovered. This assumption is invalid for structural systems with stresses that may internally redistribute upon external loading in such a way that cracks arrest and cracks faces close. Ortiz and Pandolfi[11] postulated a damage model and used an exponential constitutive law to account for such irreversibilities. A limitation of this model is that the critical energy release rates and the maximum interfacial strengths associated with Mode I, Mode II, and Mode III fracture cannot be specified separately.

The present work aims at the establishment of an exponential softening constitutive law that satisfies empirical mixed-mode delamination failure criteria for the onset and progression of delamination. An internal state variable is included in the constitutive law to permanently damage the internal surfaces that have exceeded maximum strength during the deformation process. The paper is structured as follows: (i) mixedmode fracture criteria, (i) mechanics of idealized interface material, (ii) interface finite element, (iii) finite element results, and (iv) concluding remarks.

2. Mixed-Mode Failure Criteria. A quadratic failure criterion based on interlaminar tractions has been used to predict onset of delamination $[12,13]$. To simulate the progression of delamination under mixedmode loading conditions, the power law form of the fracture criterion that includes Mode I, Mode II and Mode III interaction has been successfully used with a bilinear constitutive law $[14,15,16]$. Dávila and Camanho[17] developed a bilinear constitutive law that can be used with any mixed-mode failure criterion. To the authors' knowledge, no work has been found incorporating an empirical failure criteria into the exponential softening constitutive law. A brief description of the failure criteria used in this paper is presented next.

2.1. Criterion for the Onset of Delamination. Under pure Mode I, Mode II, or pure Mode III loading, the onset of delamination occurs when the corresponding interlaminar traction exceeds its respective maximum interfacial strength. However, under mixed-mode loading, delamination onset may occur before each traction component reaches its maximum interfacial strength. An expression that considers the interaction between the traction components under mixed-mode loading is the multi-axial stress criterion given as

$$
\bar{T}_{e}=\left(\left(\frac{T_{1}}{T_{1}^{c}}\right)^{\alpha}+\left(\frac{T_{2}}{T_{2}^{c}}\right)^{\alpha}+\left(\frac{\left\langle T_{3}\right\rangle}{T_{3}^{c}}\right)^{\alpha}\right)^{1 / \alpha}=1
$$


where $T_{j}$ is the interlaminar traction component associated with the $j$-direction, $T_{j}^{c}$ is the maximum interlaminar traction, and $\left\langle T_{3}\right\rangle=T_{3}$, if $T_{3}>0$, otherwise it is zero. This function has been included to emphasize that the normal compressive traction $T_{3}$ does not contribute to the onset of delamination. In Equation $2.1, \bar{T}_{e}$ is an effective normalized traction, and $\alpha \geq 2$ is a real number that determines the shape of the tri-dimensional failure surface. Delamination does not initiate if $\bar{T}_{e}<1$, and initiates when $\bar{T}_{e}=1$. With $\alpha=2$, one recovers the quadratic delamination interaction. The failure surface for $\alpha=2$ is a convex semi-sphere in the space of normalized tractions $T_{j} / T_{j}^{c}, j=1,2,3$. As the value of $\alpha$ is increased, the failure surface approaches a half-cube surface.

2.2. Criterion for Progression of Delamination. Delamination propagates when the energy release rate equals its critical value under pure Mode I, Mode II, or pure Mode III fracture. Generally, delamination growth occurs under mixed-mode loading. Under this type of loading, delamination growth might occur before any of the energy release rate components attains its individual critical value. The power law criterion based on the one proposed by Whitcomb[18] is

$$
\left(\frac{G_{I}}{G_{I c}}\right)^{\alpha / 2}+\left(\frac{G_{I I}}{G_{I I C}}\right)^{\alpha / 2}+\left(\frac{G_{I I I}}{G_{I I I c}}\right)^{\alpha / 2}=1
$$

where $G_{j}$ is the energy release rate under Mode $j$ fracture, and $G_{j c}$ is the single-mode critical energy release rate for $j=I, I I, I I I$. The material parameter $\alpha$ defines the shape of the failure locus. For $\alpha=2$, one recovers the linear interaction criterion[19]. The shape of the failure locus is a triangular surface. The shape of the failure surface approaches a 1/8-cube surface as $\alpha$ increases from 2. Reeder[20] evaluated different fracture criteria for mixed-mode delamination in a brittle graphite/epoxy composite, a toughened graphite/epoxy composite, and a tough graphite/thermoplastic composite using the mixed-mode bending (MMB) test specimen. The power law criterion was a reasonable fit to the test data for the three different materials. Thus, the failure criterion in Equation 2.2 is incorporated into the constitutive law of the interface material.

3. Mechanics of the Idealized Interface Material. The interfacial material is bounded by an upper surface $S^{+}$and lower surface $S^{-}$. These surfaces are assumed to coincide with a reference surface $S^{0}$ in the undeformed configuration as is shown in Figure 6.1. Thus, it is said that the interface material is of zero thickness. The surfaces $S^{ \pm}$independently displace and stretch, and are connected by a continuous distribution of nonlinear springs that act to resist the Mode I opening or Mode II and Mode III sliding of the upper and lower surface.

It is convenient to define a mid-surface $S^{m}$ where the tractions and relative displacements are evaluated. For this purpose, let us consider any two points $P^{+}$and $P^{-}$contained in $S^{+}$and $S^{-}$, which are coincident in the undeformed configuration. The locus of the midpoints $P^{m}$ of the line joining $P^{+}$and $P^{-}$define the mid-surface $S^{m}$ of the interface material. Refer to Figure 6.2. The normal and tangential components of the traction and relative displacement vector are determined by the local orientation of the mid-surface $S^{m}$. The virtual work done by the cohesive-decohesive tractions is given by

$$
\delta W_{i n t}=\iint_{S^{m}} \delta \triangle_{j} T_{j} d S^{m}
$$

for any kinematically admissible relative displacements $\triangle_{j}$, where $T_{j}$ are the interlaminar traction components acting on a unit deformed area conjugate to the relative displacements, and $S^{m}$ is the surface area. The resistive tractions that are associated to the relative displacements at the point $P^{m}$ are shown in Figure 6.2. The interlaminar normal traction is denoted $T_{3}$ and the tangential tractions are denoted $T_{1}$ and $T_{2}$. 
In the next section, the components of the relative displacements are obtained in terms of the displacement field with respect to the undeformed configuration. Next, the constitutive equations that relate the relative displacements to the traction field are presented. The kinematics and the constitutive modeling describe the mechanics of interface debonding.

3.1. Kinematics of the Interface Material. The fundamental problem introduced by the interface material is the question of how to express the virtual relative displacements between the surfaces $S^{ \pm}$in terms of virtual displacements. As shown in Figure 6.1, consider a three-dimensional space with Cartesian coordinates $X_{i}, i=1,2,3$, and let there be surfaces $S^{ \pm}$coincident with $S^{0}$ defined in this space by $X_{i}=$ $X_{i}\left(\eta_{1}, \eta_{2}\right)$, where $\eta_{1}, \eta_{2}$ are curvilinear coordinates on the surface $S^{0}$.

Let the Cartesian coordinates $x_{i}^{+}=x_{i}^{ \pm}\left(\eta_{1}, \eta_{2}\right), i=1,2,3$ describe motion of the upper and lower surfaces $S^{ \pm}$in the deformed configuration. Any point on $S^{ \pm}$in the deformed configuration is related to the same point on $S^{0}$ through

$$
x_{i}^{ \pm}=X_{i}+U_{i}^{ \pm}
$$

where $U_{i}^{ \pm}$are displacement quantities with respect to the fixed Cartesian coordinate system. The coordinates $x_{i}^{m}=x_{i}^{m}\left(\eta_{1}, \eta_{2}\right), i=1,2,3$ define the mid-surface $S^{m}$ given by

$$
x_{i}^{m}=\frac{1}{2}\left(x_{i}^{+}+x_{i}^{-}\right)=X_{i}+\frac{1}{2}\left(U_{i}^{+}+U_{i}^{-}\right)
$$

The surface $S^{m}$ is coincident with $S^{0}$ in the undeformed configuration. As mentioned earlier, the components of the relative displacement vector are evaluated at the mid-surface $S^{m}$. Therefore, the local orientation of normal and tangential unit vectors to the surface $S^{m}$ is required. This is,

$$
\begin{aligned}
& \mathbf{r}_{\mathbf{1}}=\left\{\frac{\partial \mathbf{x}_{\mathbf{1}}^{\mathbf{m}}}{\partial \eta_{\mathbf{1}}}, \frac{\partial \mathbf{x}_{\mathbf{2}}^{\mathbf{m}}}{\partial \eta_{\mathbf{1}}}, \frac{\partial \mathbf{x}_{3}^{\mathbf{m}}}{\partial \eta_{1}}\right\}^{\mathrm{T}} \\
& \mathbf{r}_{\mathbf{2}}^{\prime}=\left\{\frac{\partial \mathbf{x}_{\mathbf{1}}^{\mathbf{m}}}{\partial \eta_{\mathbf{2}}}, \frac{\partial \mathbf{x}_{\mathbf{2}}^{\mathbf{m}}}{\partial \eta_{\mathbf{2}}}, \frac{\partial \mathbf{x}_{\mathbf{3}}^{\mathbf{m}}}{\partial \eta_{\mathbf{2}}}\right\}^{\mathrm{T}}
\end{aligned}
$$

and the normal vector is simply

$$
\mathbf{r}_{3}=\mathbf{r}_{1} \times \mathbf{r}_{2}^{\prime}
$$

The tangential vectors $\mathbf{r}_{1}, \mathbf{r}_{2}^{\prime}$ may not be perpendicular in a curvilinear coordinate system so that,

$$
\mathbf{r}_{2}=\mathbf{r}_{\mathbf{3}} \times \mathbf{r}_{\mathbf{1}}
$$

For $i=1,2,3$, the normal and tangential unit vectors to the surface $S^{m}$ at a point $P^{m} \in S^{m}$ are

$$
\hat{\mathbf{r}}_{\mathbf{i}}=\frac{\mathbf{r}_{\mathbf{i}}}{\left|\mathbf{r}_{\mathbf{i}}\right|}
$$

These unit vectors define the local orthogonal coordinate system at $S^{m}$ and are related to the fixed coordinate system through the rotation matrix

$$
\mathbf{R}=\left[\hat{\mathbf{r}}_{1}, \hat{\mathbf{r}}_{2}, \hat{\mathbf{r}}_{3}\right]
$$

The normal and tangential components of the relative displacements vector expressed in terms of the displacement field is,

$$
\triangle_{i}=R_{j i}\left(x_{j}^{+}-x_{j}^{-}\right)=R_{j i}\left(U_{j}^{+}-U_{j}^{-}\right)
$$


where $R_{j i}$ are components of the rotation matrix. Since $x_{i}^{m}$ depends on the displacements $U_{i}^{ \pm}$, the rotation matrix also depends on $U_{i}^{ \pm}$. Therefore, the virtual relative displacement are expressed in terms of the virtual displacements as follows,

$$
\delta \triangle_{i}=R_{j i}\left(\delta U_{j}^{-}-\delta U_{j}^{-}\right)
$$

Equation 3.11 is substituted into Equation 3.1 to obtain the expression of the internal virtual work in terms of the virtual displacements. This form of the internal virtual work is convenient for the finite element formulation. In addition, the differential surface area of the mid-surface $d S^{m}$ in the deformed configuration is expressed in the form,

$$
d S^{m}=M d S^{0}
$$

where $d S^{0}$ is the differential undeformed surface area, and $M$ is a function of the displacement field $U_{i}^{ \pm}$.

3.2. Constitutive Equations for the Interface Material. The stress singularities at the crack-tip in the linear elasticity solutions, stemming from the sharp slit approximation, cannot be reconciled with any realistic local rupture process. From the molecular theory of strength it is known that there exists stress limits for which molecular bond rupture occurs. The softening-type of cohesive zone model is intended to represent the degradation of the material ahead of the crack-tip. It captures strength-based bond weakening, and fracture-based bond rupture. The mechanics of the delamination process comprises three interrelated phases: (i) the initiation of delamination, (ii) the evolution of the degradation zone, (iii) and the delamination growth. The first phase that takes place is the initiation of delamination, and it is based on a stress limit determined experimentally. A stress measure that is used as the limiting value, may involve an interaction of interlaminar stresses such as that in Equation 2.1. The second event is the development of a zone ahead of the crack-tip that experiences intense deformation such as plastic deformation in metals, elongated voids that contains a fibrous structure bridging the crack faces in polymers (crazing), and high density of tiny cracks in brittle ceramics. The molecular bonds are weakened and the nonlinear softening behavior is confined in this degradation zone, or process zone. The third event, is the growth of delamination, bond-rupture, and it is based on a fracture criteria such as Equation 2.2. The constitutive equations to be developed, mathematically describe these three delamination phases. The focus of this section is to develop the constitutive equation for single-bond rupture based on continuum damage mechanics approach. This particular case is extended to mixed-mode delamination. The constitutive equations that are postulated in this section, are shown to satisfy the failure criteria for initiation and progression of delamination presented in the previous section.

Assume that the two material points $P^{+}$and $P^{-}$contained in $S^{+}$and $S^{-}$as shown in Figure 6.2 are connected with a spring. The points are coincident when the spring is unstretched, and a high initial spring stiffness restrains the relative displacement of these material points. Under isothermal conditions, the traction $T$ that acts to resist the relative displacement of these material points is due to stretching $\triangle$ of the spring, and is expressed as

$$
T(\triangle)=T_{c} \bar{\triangle} \exp \left(\frac{1-\bar{\triangle}^{\beta}}{\beta}\right)
$$

where $\bar{\triangle}=\triangle / \triangle^{c}$, and $T^{c}$ is the maximum bonding strength that occurs at the critical stretching value $\triangle^{c}$. The parameter $\beta$ with $\beta \geq 1$ and $\beta \in \mathrm{R}^{+}$defines the stretching range for which the bond is weakened before complete rupture occurs. It is in this range, that damage accumulates. In Figure 6.3, the traction-stretching curve is shown for different values of the parameter $\beta$. The work of debonding per unit area, $G_{c}$, is given by 
the area under the traction-stretching curve, or,

$$
\begin{aligned}
G_{c} & =\int_{0}^{\infty} T(\triangle) d \triangle \\
& =T^{c} \triangle^{c} \beta^{(2-\beta) / \beta} \Gamma\left[\frac{2}{\beta}\right] \exp \left(\frac{1}{\beta}\right)
\end{aligned}
$$

where $\Gamma[z]$ is the Euler gamma function of argument $z$. By prescribing $T^{c}, G_{c}$, and $\beta$ in Equation 3.14, the parameter $\triangle^{c}$ can be computed. The exponential function in Equation 3.13 is a suitable representation of a softening constitutive law because with increasing stretching of the spring $\triangle$, the traction $T$ increases to a peak value $T^{c}$ and then decreases until complete debonding occurs. Equation 3.13 is only valid for monotonically increasing separation because the work due to stretching is recoverable on unloading.

An internal state variable $\tilde{d}$ that tracks the damage state of the spring needs to be included in Equation 3.13 to account for irreversible effects. In the following irreversible law an elastic damage model instead of a plastic damage model is assumed,

$$
T(\triangle)=T^{c} \bar{\triangle} \exp \left(\frac{2-\bar{\triangle}^{\beta} / \tilde{d}-\tilde{d}}{\beta}\right)
$$

Within the framework of continuum damage mechanics, it is possible to impose restrictions on $\tilde{d}$. It must increase as a function of time because thermodynamics requires that the irreversible dissipation associated with the debonding process remains semi-positive, i.e., $\tilde{\tilde{d}} \geq 0$. An equivalent mathematical expression at a discrete time $t_{i}$ is

$$
\tilde{d}^{\left(t_{i}\right)}=\max \left(1, \tilde{d}^{\left(t_{i-1}\right)}, \bar{\triangle}_{\left(t_{i}\right)}^{\beta}\right), \tilde{d}^{(0)}=1
$$

with $t_{i}>t_{i-1}$. If the spring is assumed undamaged at $t=t_{0}$, then the initial condition is $\tilde{d}^{\left(t_{0}\right)}=1$. Equation 3.15 is equivalent to Equation 3.13 if no damage occurs, $\tilde{d}=1$, or for monotonic increasing loading, $\tilde{d}=\bar{\triangle}_{\left(t_{i}\right)}^{\beta}$. Unloading does not occur linearly to the origin, but with an exponential form. The energy of dissipation associated to fatigue is neglected in this work. This assumption is valid in the case of a spring that undergoes a small number of loading-unloading cycles.

Equations 3.15 and 3.16 with $\beta=1$ are used for the traction-stretching curve shown in Figure 6.4. The points on the curve labeled $1, \ldots, 6$ in this figure, represent a possible loading-unloading cycle of the spring connecting terminal points $P^{ \pm}$. The spring is unstretched at point 1 . With increasing stretching cohesive traction develops to resist the separation. Point 2 is in the stiffening portion of the constitutive law, and the action of the spring prevents much separation of points $P^{ \pm}$. The onset of delamination occurs at point 3 , where the traction attains its maximum value. As the spring is stretched beyond the onset of delamination to point 4 , damage accumulates in the spring and the traction gradually decreases. Assume unloading commences at point 4 , then the spring begins to contract to point 5 . If loading commences from point 5 , the spring is stretched again to point 6 on the original softening portion of the constitutive law. Continued loading from point 6 is along the original softening portion of the constitutive law. The traction eventually vanishes as the spring is stretched substantially beyond point 6 .

Equations 3.15 and 3.16 are extended to the mixed-mode delamination case. To develop the constitutive equations, it is convenient to normalize the relative displacements $\triangle_{j}$ and the tractions $T_{j}$ with respect to the critical separation values $\triangle_{j}^{c}$ and the maximum interfacial strengths $T_{j}^{c}$. That is,

$$
\bar{\triangle}_{j}=\triangle_{j} / \triangle_{j}^{c}, \quad \bar{T}_{j}=T_{j} / T_{j}^{c}
$$


In reference to Figure 6.2, the components of the normalized relative displacements between $P^{ \pm}$with respect to the orientation of the surface $S^{m}$ at a point $P^{m}$ is,

$$
\mathbf{v}=\bar{\triangle}_{1} \hat{\mathbf{r}}_{1}+\bar{\triangle}_{2} \hat{\mathbf{r}}_{2}+\bar{\triangle}_{3} \hat{\mathbf{r}}_{3}
$$

where $\hat{\mathbf{r}}_{\mathbf{1}}, \hat{\mathbf{r}}_{\mathbf{2}}, \hat{\mathbf{r}}_{3}$ are the unit vectors tangent and normal to the surface $S^{m}$ at a point $P^{m}$. An effective relative displacement $\lambda$ is defined by the norm of $\mathbf{v}$

$$
\lambda=\sqrt{\bar{\triangle}_{1}^{2}+\bar{\triangle}_{2}^{2}+\bar{\triangle}_{3}^{2}}
$$

We assume that the normalized scalar traction $\bar{T}_{v}$ acts along the direction of $\mathbf{v}$ to resist the effective relative displacement $\lambda$. The proposed constitutive law for the interface material is defined along $\mathbf{v}$,

$$
\bar{T}_{v}\left(\bar{\triangle}_{1}, \bar{\triangle}_{2}, \bar{\triangle}_{3}\right)=\lambda Q\left(\bar{\triangle}_{1}, \bar{\triangle}_{2}, \bar{\triangle}_{3}\right)
$$

where $Q$ is a decreasing function of any of the normalized relative displacements $\bar{\triangle}_{j}, j=1,2,3$. The components of the traction acting along $\mathbf{v}$, normal and tangent to the mid-surface $S^{m}$ at a point $P^{m}$ is

$$
\bar{T}_{j}=\bar{T}_{v} \hat{\mathbf{r}}_{j} \cdot \frac{\mathbf{v}}{\|\mathbf{v}\|}=\bar{\triangle}_{j} Q
$$

for $j=1,2,3$. The function $Q$ is chosen to satisfy the multi-axial stress criterion in Equation 2.1 for the onset of delamination and the mixed-mode fracture criterion in Equation 2.2 and is given by

$$
Q=\exp \left(\frac{2-\mu^{\beta} / \tilde{d}-\tilde{d}}{\beta}\right)
$$

In the latter equation, the scalar mixed-mode parameter $\mu$ is defined such that it couples the normalized relative displacements for the opening and sliding modes; i.e.,

$$
\mu=\left(\left|\bar{\triangle}_{1}\right|^{\alpha}+\left|\bar{\triangle}_{2}\right|^{\alpha}+\left\langle\bar{\triangle}_{3}\right\rangle^{\alpha}\right)^{1 / \alpha}
$$

where $\left|\triangle_{i}\right|$ is the absolute value function, and $\left\langle\triangle_{1}\right\rangle=\triangle_{1}$ if $\triangle_{1}>0$, otherwise it is zero. The material parameter $\alpha$ defines the shape of the failure surface for the onset and progression of delamination. The internal state variable $\tilde{d}$ is given by,

$$
\tilde{d}^{\left(t_{i}\right)}=\max \left(1, \tilde{d}^{\left(t_{i-1}\right)}, \mu_{(t)}^{\beta}\right), \tilde{d}^{(0)}=1
$$

The constitutive equations are slightly modified to take into consideration the mechanical behavior of the interface if penetration of surfaces $S^{ \pm}$is detected. Under these contact conditions the surfaces $S^{ \pm}$are assumed smooth so that frictional effects can be neglected. When contact is formed between two smooth surfaces of adjacent lamina, the equilibrium largely depends upon the distribution of elastic forces in the contacting lamina. Adjacent lamina surfaces are under contact at a point $P^{m}, P^{m} \in S^{m}$ if the relative displacement $\triangle_{3}$ between $P^{ \pm}$is less than zero. For $\triangle_{3}<0$, a large repulsive traction $T_{3}$ develops to avoid interpenetration of the surfaces $S^{ \pm}$at $P^{m}$. From Equations 3.21 to 3.24 we obtain the final form of the mixed-mode constitutive equations as

$$
\begin{aligned}
\left\{\begin{array}{c}
\bar{T}_{1} \\
\bar{T}_{2} \\
\bar{T}_{3}
\end{array}\right\} & =\left\{\begin{array}{c}
\bar{\triangle}_{1} \\
\bar{\triangle}_{2} \\
\left\langle\bar{\triangle}_{3}\right\rangle
\end{array}\right\} \exp \left(\frac{2-\mu^{\beta} / \tilde{d}-\tilde{d}}{\beta}\right) \\
& +\left\{\begin{array}{c}
0 \\
0 \\
-\left\langle-\bar{\triangle}_{3}\right\rangle
\end{array}\right\} \exp \left(\frac{1+\kappa\left|\bar{\triangle}_{3}\right|^{\beta}}{\beta}\right)
\end{aligned}
$$


where $\kappa$ is an interpenetration factor to magnify the repulsive force $T_{3}$, and it is chosen arbitrarily in the range $\kappa>1$. Equations 3.25 and 3.24 reduce to Equations 3.15 and 3.16, respectively, for single-mode delamination.

The empirical parameters governing the constitutive equations in 3.25 are the critical energy release rates $G_{I c}, G_{I I c}, G_{I I I c}$; the maximum interfacial strengths $T_{1}^{c}, T_{2}^{c}, T_{3}^{c}$; the critical separation values $\triangle_{1}^{c}, \triangle_{2}^{c}, \triangle_{3}^{c}$; and the parameter $\beta$. These may be specified based on atomistic models of separation or on a phenomenological basis depending whether the separation process is governed by ductile void coalescence or a brittle cleavage mechanism. By specifying the critical energy release rates and the maximum interfacial strengths, one can obtain the critical separation values. The path independent $J$-integral along a boundary that contains the interface material can be used to show that the area under the traction versus separation curve is the work of fracture per unit area. Equation 3.14 under pure Mode I, Mode II, or Mode III fracture, is used to obtain the critical separation values $\triangle_{j}^{c}, j=1,2,3$.

Proof. The exponential constitutive law as specified by Equations 3.24 and 3.25 satisfy Equation 2.1 for the onset of delamination, and Equation 2.2 for the progression of delamination.

For simplicity, monotonically increasing loading is assumed, i.e., $\tilde{d}=\max \left(1, \mu^{\beta}\right)$. The effect of interpenetration is also neglected, $\triangle_{3}>0$. For the onset of delamination, the components of the traction vector in Equation 3.25 are substituted into Equation 2.1 to obtain the effective traction $\bar{T}_{e}$ as

$$
\begin{aligned}
\bar{T}_{e} & =\left(\left(\bar{\triangle}_{1}^{\alpha}+\bar{\triangle}_{2}^{\alpha}+\bar{\triangle}_{3}^{\alpha}\right) \exp \left(\alpha \frac{1-\mu^{\beta}}{\beta}\right)\right)^{1 / \alpha} \\
& =\mu \exp \left(\frac{1-\mu^{\beta}}{\beta}\right)
\end{aligned}
$$

This equation is analogous to Equation 3.13 for single-mode delamination. At the initiation of delamination we set $\bar{T}_{e}=1$ in Equation 3.26, to find the only solution which is $\mu^{\beta}=1$. Hence, the relative displacement $\mu=1$ at the onset of delamination when $\bar{T}_{e}=1$. Therefore, the proposed constitutive law, Equation 3.25, satisfies Equation 2.1 for the initiation of delamination.

For the progression of delamination, proportional straining is assumed. The relative displacement associated to the sliding Mode II and Mode III are written as $\bar{\triangle}_{1}=\xi_{2} \bar{\triangle}_{3}$ and $\bar{\triangle}_{2}=\xi_{3} \bar{\triangle}_{3}$ with $\xi_{2}$ and $\xi_{3}$ fixed during the loading history. The terms in Equation 2.2 are evaluated as follows,

$$
\begin{aligned}
\left(\frac{G_{I}}{G_{I c}}\right)^{\alpha / 2} & =\left(\frac{\int_{0}^{\bar{\triangle}_{3}} T_{3}\left(\bar{\triangle}_{1}, \bar{\triangle}_{2}, \bar{\triangle}_{3}\right) d \bar{\triangle}_{3}}{\int_{0}^{\infty} T_{3}\left(0,0, \bar{\triangle}_{3}\right) d \bar{\triangle}_{3}}\right)^{\alpha / 2} \\
& =\left(\frac{1}{\left(1+\xi_{2}^{\alpha}+\xi_{3}^{\alpha}\right)^{2 / \alpha}}+\phi_{1}\left(\bar{\triangle}_{3}\right)\right)^{\alpha / 2} \\
\left(\frac{G_{I I}}{G_{I I C}}\right)^{\alpha / 2} & =\left(\frac{\int_{0}^{\bar{\triangle}_{1}} T_{1}\left(\bar{\triangle}_{1}, \bar{\triangle}_{2}, \bar{\triangle}_{3}\right) d \bar{\triangle}_{1}}{\int_{0}^{\infty} T_{1}\left(\bar{\triangle}_{1}, 0,0\right) d \bar{\triangle}_{1}}\right)^{\alpha / 2} \\
& =\left(\frac{\xi_{2}^{2}}{\left(1+\xi_{2}^{\alpha}+\xi_{3}^{\alpha}\right)^{2 / \alpha}}+\phi_{2}\left(\bar{\triangle}_{3}\right)\right)^{\alpha / 2}
\end{aligned}
$$




$$
\begin{aligned}
\left(\frac{G_{I I I}}{G_{I I I c}}\right)^{\alpha / 2} & =\left(\frac{\int_{0}^{\bar{\triangle}_{2}} T_{2}\left(\bar{\triangle}_{1}, \bar{\triangle}_{2}, \bar{\triangle}_{3}\right) d \bar{\triangle}_{3}}{\int_{0}^{\infty} T_{2}\left(0, \bar{\triangle}_{2}, 0\right) d \bar{\triangle}_{2}}\right)^{\alpha / 2} \\
& =\left(\frac{\xi_{3}^{2}}{\left(1+\xi_{2}^{\alpha}+\xi_{3}^{\alpha}\right)^{2 / \alpha}}+\phi_{3}\left(\bar{\triangle}_{3}\right)\right)^{\alpha / 2}
\end{aligned}
$$

where $\phi_{j}\left(\bar{\triangle}_{3}\right), j=1,2,3$ are exponential decaying functions with increasing $\bar{\triangle}_{3}$. The progression of delamination occurs when the functions $\phi_{j}\left(\bar{\triangle}_{3}\right), j=1,2,3$ are virtually zero. Adding the last three equations shows that the power criterion in Equation 2.2 is satisfied.

4. Interface Finite Element. The formulation for the interface element is based on the work of Beer [21]. An iterative solution procedure is necessary because of the geometrical and material nonlinearities of the interface material. The objective of this section is to obtain the tangent stiffness matrix $\mathbf{K}_{\mathrm{t}}^{\mathrm{e}}$ and the internal force vector $\mathbf{f}_{\mathrm{int}}^{\mathrm{e}}$ required in the nonlinear solution procedure.

A $2 n$-noded isoparametric interface element with $6 n$ degrees of freedom and applicable to three dimensional analysis is used. The element consists of an upper and lower surface $S_{e}^{ \pm}$with $n$-nodes each. The natural coordinate system is $\eta_{1}$ and $\eta_{2}$. For the surfaces $S_{e}^{ \pm}$, node $j$ has three translational degrees of free$\operatorname{dom} q_{1 j}^{ \pm}, q_{2 j}^{ \pm}, q_{3 j}^{ \pm}$with the first subscript implying the associated global direction. The nodal displacement vector $\mathbf{q}$ is arranged as follows,

$$
\begin{aligned}
& \mathbf{q}=\left\{\mathbf{q}^{+}, \mathbf{q}^{-}\right\}^{\mathrm{T}} \\
& \mathbf{q}^{ \pm}=\left\{q_{11}^{ \pm}, q_{21}^{ \pm}, q_{31}^{ \pm}, \ldots, q_{1 n}^{ \pm}, q_{2 n}^{ \pm}, q_{3 n}^{ \pm}\right\}^{\mathrm{T}}
\end{aligned}
$$

The displacement field $U_{j}^{ \pm}\left(\eta_{1}, \eta_{2}\right), j=1,2,3$ of the upper and lower surfaces of the element is arranged in the vector $\mathbf{U}^{ \pm}$. The displacement vector $\mathbf{U}^{ \pm}$is related to the global displacement degrees of freedom vector $\mathbf{q}^{ \pm}$as,

$$
\mathbf{U}^{ \pm}=\mathbf{N} \mathbf{q}^{ \pm}
$$

where $\mathbf{N}$ is a $3 \times 3 n$ shape function matrix. Substituting Equation 4.2 into Equation 3.11 gives the virtual relative displacement vector $\delta \vec{\triangle}$ in terms of $\delta \mathbf{q}^{ \pm}$,

$$
\delta \vec{\triangle}=\left[\mathbf{R}^{\mathrm{T}} \mathbf{N} \delta \mathbf{q}^{+},-\mathbf{R}^{\mathrm{T}} \mathbf{N} \delta \mathbf{q}^{-}\right]
$$

It is convenient to define the $3 \times 3 n$ matrix $\mathbf{B}_{\mathbf{s}}$,

$$
\mathbf{B}_{\mathbf{s}}=\mathbf{R}^{\mathrm{T}} \mathbf{N}
$$

and the $3 \times 6 n$ relative-displacement/displacement matrix $\mathbf{B}$,

$$
\delta \vec{\triangle}=\left[\mathbf{B}_{\mathrm{s}},-\mathbf{B}_{\mathrm{s}}\right] \delta \mathbf{q}=\mathbf{B} \delta \mathbf{q}
$$

The internal force vector of the interface element is obtained by substituting Equation 4.5 in 3.1,

$$
\delta W_{\text {int }}^{e}=\delta \mathbf{q}^{\mathrm{T}} \iint_{S_{e}^{m}} \mathbf{B}^{\mathrm{T}} \mathbf{T} d S_{e}^{m}=\delta \mathbf{q}^{\mathrm{T}} \mathbf{f}_{\mathrm{int}}^{e}
$$

where $\mathbf{T}$ is the traction vector acting on the deformed mid-surface and the integration is performed over the mid-surface of the deformed element. The tangent stiffness matrix stems from the linearization of the internal force vector and is obtained using Taylor's series expansion about the approximation $\mathbf{q}^{(i)}$

$$
\mathbf{f}_{\mathrm{int}}^{e}\left(\mathbf{q}^{(i)}+\triangle \mathbf{q}\right) \approx \mathbf{f}_{\mathrm{int}}^{e}\left(\mathbf{q}^{(i)}\right)+\left[\frac{\partial \mathbf{f}_{\text {int }}^{e}}{\partial \mathbf{q}}\right]_{\mathbf{q}=\mathbf{q}^{(i)}} \Delta \mathbf{q}+\ldots
$$


where $i$ is the iteration number.

In numerical analyses, the internal force vector needs to be computed accurately, and the tangent stiffness matrix may be computed approximately. The computation of the tangent stiffness matrix is intensive and a very accurate expression is not required. Therefore, the derivative of the relative-displacement matrix/displacement matrix with respect to the nodal displacements are neglected. In addition, the partial derivatives of $M$ in Equation 3.12 with respect to $\mathbf{q}$ are neglected. Thus, from Equation 4.7, the approximate $6 n \times 6 n$ tangent stiffness matrix is

$$
\begin{aligned}
& \mathbf{B}_{s}=\mathbf{B}^{+}=\mathbf{B}^{-} \\
& \tilde{\mathbf{B}}=\left[\mathbf{B}_{\mathrm{s}},-\mathbf{B}_{\mathrm{s}}\right]
\end{aligned}
$$

where $\tilde{\mathbf{B}}$ implies approximation to $\mathbf{B}$.

$$
\mathbf{K}_{\mathrm{t}}^{e}=\frac{\partial \mathbf{f}_{\mathrm{int}}^{e}}{\partial \mathbf{q}} \approx \iint_{S_{e}^{m}} \mathbf{B}^{\mathrm{T}} \mathbf{D B} d S_{e}^{m}
$$

where $\mathbf{D}$ is the material tangent stiffness, and is later defined in detail. Equation 4.9 is rewritten using the relation in Equation 4.8,

$$
\mathbf{K}_{\mathrm{t}}^{e}=\left[\begin{array}{cc}
\mathbf{K}_{s} & -\mathbf{K}_{s} \\
-\mathbf{K}_{s} & \mathbf{K}_{s}
\end{array}\right]
$$

where $\mathbf{K}_{s}$ is a $3 n \times 3 n$ submatrix defined as

$$
\mathbf{K}_{s}=\iint_{S_{e}^{m}} \mathbf{B}_{\mathbf{s}}^{\mathrm{T}} \mathbf{D} \mathbf{B}_{\mathbf{s}} d S_{e}^{m}
$$

The approximations for the tangent stiffness matrix save computational time.

4.1. Material Tangent Stiffness. The components of the material tangent stiffness $\mathbf{D}$ are obtained in the incremental form,

$$
\delta T_{i}=\frac{\partial T_{i}}{\partial \triangle_{j}} \delta \triangle_{j}=D_{i j} \delta \triangle_{j}
$$

First consider the case in which there is no interpenetration, that is, for $\triangle_{3}>0$. The components of $\mathbf{D}$ are obtained by differentiation of Equation 3.25 according to Equation 4.12,

$$
D_{i j}=\frac{T_{i}^{c}}{\triangle_{j}^{c}}\left(\delta_{i j}-\frac{\bar{\triangle}_{i} \bar{\triangle}_{j}}{\tilde{w} \mu^{\alpha-\beta}}\left|\bar{\triangle}_{j}\right|^{\alpha-2}\right) Q
$$

where $\delta_{i j}$ is the Kronecker delta, $Q$ is given by Equation 3.22, and $\tilde{w}$ is defined by,

$$
\tilde{w}=\left\{1 \quad \text { if } \quad \tilde{d}=\mu^{\beta} \tilde{d} \quad \text { if } \quad \tilde{d}>\mu^{\beta}\right.
$$

Now consider the case for which interpenetration is detected, that is, $\Delta_{3}<0$. The non-zero components of $\mathbf{D}$ are given by Equation 4.13 for $i, j=1,2$ and the component related to interpenetration,

$$
D_{33}=K_{0}\left(1+\kappa\left|\bar{\triangle}_{3}\right|^{\beta}\right) \exp \left(\frac{\kappa\left|\bar{\triangle}_{3}\right|^{\beta}}{\beta}\right)
$$

where $K_{0}=T_{3}^{c} \exp (1 / \beta) / \triangle_{3}^{c}$. The range of the values of $D_{33}$ should be restricted by two conditions: (1) A small $D_{33}$ induces interpenetration, and (2) a large $D_{33}$ produces ill-conditioned matrices. $A$ list of references on these restrictions is given by Dávila et al[13]. The value of $D_{33}$ should be in the range,

$$
10^{6} \mathrm{~N} / \mathrm{mm}^{3}<D_{33}<10^{7} \mathrm{~N} / \mathrm{mm}^{3}
$$


The upper bound of the condition cannot be guaranteed because of the exponential nature of Equation 4.15. Therefore, for $\triangle_{3}<0$, the expressions $T_{3}$ and $D_{33}$ are modified to have the form

$$
T_{3}=K_{0} \triangle_{3}, \quad D_{33}=K_{0}
$$

and $K_{0}=T_{3}^{c} \exp (1 / \beta) / \triangle_{3}^{c}$.

The material tangent stiffness is non-symmetric, and can be positive definite, semi-definite, or negative definite. For $\mu>1$, the matrix $D_{i j}$ is negative definite. The material tangent stiffness matrix has properties of an anisotropic material, one which has strong dependence on the relative displacements in all directions. For single-mode delamination, $\mathbf{D}$ is fully diagonal, otherwise, some of the off-diagonals are non-zero.

4.2. Consistent and Inconsistent Tangent Stiffness. For the full-Newton-Raphson nonlinear solution procedure, the consistent tangent stiffness matrix is used in the finite element analysis. However, when softening constitutive laws with the consistent tangent stiffness are employed, the tangent stiffness matrix is often ill-conditioned and a converged solution may not be obtained[22]. An alternative solution is to refine the mesh ahead of the crack-tip or to decrease the maximum interfacial strength[15, 23]. Refining the mesh size increases the computational time, and lowering the maximum interface strength can result in a premature initiation of delamination[7]. Alternatively, researchers often utilize a positive definite matrix such as the material secant stiffness when dealing with softening constitutive laws. However, a large number of iterations results in using the material secant stiffness. As an alternative, three different modifications to the tangent stiffness matrix eliminate these convergence difficulties while a converged solution can be obtained in a small number of iterations:

1. Equation $4.8, K_{i i}^{e}=\max \left(0, K_{i i}^{e}\right), i=1,2, \ldots, 2 n$

2. Equation $4.9, K_{s_{i i}}=\max \left(0, K_{s_{i i}}\right), i=1,2, \ldots, n$

3. Equation $4.13, D_{i i}=\max \left(0, D_{i i}\right), i=1,2,3$

The convergence rate of option 1 is better than option 2 , and the convergence rate of option 2 is better than option 3. If the mesh is coarse, it is better to choose option 3.

4.3. Contact Elements. Interface elements were developed to model initial delaminated surfaces. All the components of the material tangent stiffness is zero, except for the case in which interpenetration is detected. If interpenetration is detected Equation 4.17 is used. Thus, these interface elements act like contact elements.

5. Finite Element Results. Numerical results are presented for quasi-static loading and unloading of the double cantilever beam (DCB), the end load split (ELS), end notch flexure (ENF), and fixed ratio mixed mode (FRMM) fracture test specimens. Results are also presented for quasi-static loading of the mixed mode bending (MMB). Mode I fracture occurs in the DCB, Mode II occurs in the ELS and ENF, and Mode I and II occur in the FRMM and MMB. The fracture test specimen configurations are shown in Figure 6.5.

Mode I and mixed-mode test specimens are modeled with the laminate stacking sequence $\left[0_{2}^{\circ}\right]$ and the unidirectional material properties of Graphite-Epoxy listed in Table 6.1. An isotropic material with $E=E_{11}$ and $\nu=\nu_{12}$ are used for the Mode II test specimens rather than composite. The maximum interfacial strength and the critical energy release rates are listed in Table 6.2. The geometrical properties are the length $L=100 \mathrm{~mm}$, the arm thickness $h=1.5 \mathrm{~mm}$, and width $B=10 \mathrm{~mm}$. For the DCB, the geometrical properties are different from the other test specimen configurations: $L=150 \mathrm{~mm}, h=1.5 \mathrm{~mm}$, and $B=20 \mathrm{~mm}$. The initial crack length $a_{0}$ of each test specimen is: DCB - $50 \mathrm{~mm}$, ENF - $30 \mathrm{~mm}$, ELS $50 \mathrm{~mm}, \mathrm{FRMM}-40 \mathrm{~mm}$, and MMB - $20 \mathrm{~mm}$. 
The interface elements are positioned between the upper $0^{\circ}$ lamina and the lower $0^{\circ}$ lamina. Delamination is constrained to grow in the plane between the upper and lower laminates. Interface elements with contact properties were placed along the initial crack length and interface elements formulated with the softening law are placed along the bonded length. The upper and lower laminates are modeled with C3D8I incompatible-mode 8 node solid element available in ABAQUS. Each lamina is modeled with one element through the thickness, 100 elements along the length of the laminate, and one element across the width. See Figure 6.6a. For the DCB, three elements along the width are used. The eight node isoparametric interface element for three-dimensional analysis shown in Figure 6.6b is compatible with C3D8I solid element. The element was implemented in the commercial finite element code ABAQUS as an UEL subroutine. Three point Gauss integration is used for the computation of the tangent stiffness matrix and internal force vector.

An incremental-iterative approach is adopted for the nonlinear finite element analysis, and the Newton's method available in ABAQUS is used to trace the loading path of the specimens with a displacement-control analysis. For the MMB, the Riks method available in ABAQUS is used. The modification to the tangent stiffness matrix used is option 2 discussed in the section of interface elements. The response of the test specimens is characterized by the load-deflection curve. A typical finite element model of one of the test specimens consists of about 300 elements, and 2000 degrees of freedom. The computational time required was about 1200 seconds of CPU time on a Sun Solaris 2000. The average number of iterations per load increment is 7 .

The finite element solutions are compared to the beam analytical solutions derived from linear elastic fracture mechanics. The analytical solutions for the DCB and ENF are given by Mi et al.[15], and for the FRMM and ELS are given by Chen et al.[23]. The finite element solutions for the MMB test specimen are compared to the analytical solution in the appendix.

The DCB shown in Figure 6.5a is used to determine the interlaminar fracture toughness in Mode I. The displacement $w$ is symmetrically applied, equal and opposite at the tip of the upper and lower arm of the DCB test specimen. The corresponding reaction force $P$ is computed. The other end of the specimen is clamped. The response of the DCB is shown in Figure 6.7a. For a loading-unloading cycle, excellent agreement of the FEM results are obtained compared to to the closed form solutions and to the experimental data([13]). The contour plot of the effective von Mises stress of the DCB is shown from the top view near the delamination front in Figure $6.7 \mathrm{~b}$. The black strip is a region of low stress values, indicating that delamination has occurred. The gray strip is a region of intermediate stress values, and is where the material points are softening. The boundary of the black and gray strip is the location of the crack-tip. The white strip is the location of high stresses, and is the region where onset of delamination is occurring. Non-self-similar crack growth occurs because of the anticlastic bending effect. The tangent stiffness matrix in the Newton-Raphson methods did not converge at the limit point because of the large value of the maximum interfacial strength, $T^{c}$. Any of the modifications to the tangent stiffness matrix discussed in the section of interface elements, produced converged solutions.

The ELS and ENF are shown in Figure $6.5 \mathrm{~b}$ and $6.5 \mathrm{c}$ are used to determine the interlaminar fracture toughness in Mode II. For the ELS, the load $P$ is applied at the tip such that the lower arm of the ELS remains in contact with upper arm. The other end of the specimen is clamped. The ENF specimen is simply supported, and the downward vertical displacement $w_{2}$ is specified at the mid-span of the specimen. The corresponding reaction force $P_{2}$ is computed. The response of the ELS and ENF are shown in Figure 6.8a and $6.8 \mathrm{~b}$, respectively. For a loading-unloading cycle, excellent agreement of the FEM results are obtained compared to the closed form solutions. 
The FRMM is shown in Figure 6.5d, and is used to evaluate empirical failure criteria for mixed-mode delamination. The displacement $w$ is specified at the tip of the upper arm and the corresponding reaction force $P$ is computed. Mode $\mathrm{I}$ is $43 \%$ and Mode II is $57 \%$. The response for $\alpha=2$ and $\alpha=4$ (see Equation 2.1 and 2.2 ) is shown in Figure $6.9 \mathrm{a}$ and $6.9 \mathrm{~b}$ respectively. For a loading-unloading cycle, excellent agreement of the FEM results are obtained compared to the closed form solutions.

The MMB is shown in Figure 6.5c, and is used to evaluate empirical failure criteria for mixed-mode delamination. The length of the lever arm $c$ described in the report by Reeder[20] is chosen such that the mixed mode ratio from pure Mode I to pure Mode II can be varied. In this paper, $c=43.72 \mathrm{~mm}$, so that the Mode I and Mode II contributions are 50\% each. The MMB is simply supported, and two proportional loads are applied. The load $P_{1}$ is applied upward at the tip of the upper arm, and another load $P_{2}$ is applied downward at the mid-span. During the loading, the ratio $P_{1} / P_{2}=2 c /(2 c+L)$ is fixed. The responses for $\alpha=4$ and $\alpha=2$ are shown in Figure 6.10a and 6.10b. The finite element response is compared to the analytical solutions in the appendix. In the first analysis, geometric nonlinearity is used. In the second analysis both geometric linearity and nonlinearity are compared with the analytical solutions. The discrepancies on the response corresponding to the stable crack growth of the load-deflection response are because the analytical solution does not consider the effects of geometric nonlinearities. Excellent agreement is obtained with the analytical solutions.

6. Concluding Remarks. The mechanics of an idealized interface material is presented. The kinematical relations and the irreversible constitutive law mathematically describe the mechanics of the delamination process. The delamination process comprises three interrelated phases: the initiation of delamination, the evolution of the degradation zone, and the delamination growth. It predicts initiation of delamination based on a multi-axial stress criterion, and progression of delamination based on an empirical mixed-mode fracture criterion. A damage parameter is included to prevent the restoration of the previous cohesive state between the interfacial surfaces. The constitutive law is implemented with interface elements using the principal of virtual work. To demonstrate the irreversibility capability of the constitutive law, steady-state crack growth is simulated for quasi-static loading-unloading cycle of various fracture test specimen configurations. The finite element solutions are in excellent agreement with the analytical solutions.

\section{REFERENCES}

[1] E. F. Rybicki And M. F. Kanninen, A Finite Element Calculation of Stress Intensity Factors by a Modified Crack Closure Integral. Eng. Fracture Mech., 9, pages 931-938, 1977.

[2] I. S. RAJU, Calculation of Strain-Energy Release Rates with Higher Order and Singular Finite Elements. Eng. Fracture Mech, 28, pages 251-274, 1987.

[3] D. S. Dugdale, Yielding of Steel Sheets Containing Clits. J. Mech. Phys. Solids, 8, pages 100-104, 1960.

[4] G. I. Barrenblatt, The Mathematical Theory of Equilibrium of Cracks in Brittle Fracture. Adv. Appl. Mech., 9, pages 55-129, 1962.

[5] A. Hilleborg, M. Modeer, And I.E. Petersson, Analysis of Crack Formation and Crack Growth in Concrete by Means of Fracture Mechanics and Finite Elements. Cement \& Concrete Res., 6, pages 773-782, 1976.

[6] A. Needleman, A Continuum Model for Void Nucleation by Inclusion Debonding. J. Appl. Mech., 54, pages 525-531, 1987. 
[7] V. K. Goyal-Singhal and E.R. Johnson, Computational Issues in Modeling the Delamination Process using Interface Finite Elements. In Proceedings of the American Society for Composites, 16th Technical Conference, (9-12 September 2001, Blacksburg, VA) Technomic Publishing Co., Inc., Lancaster, PA, CD-ROM, 2001.

[8] J. H. Rose, J. Ferrante, And R. J. Smith, Universal Binding Energy Curves for Metals and Bimetallic Interfaces. Physical Review Letters, 47(9), pages 675-678, 1981.

[9] X. Xu and A. Needleman, Numerical Simulations of Fast Crack Growth in Brittle Solids. J. Mech. Phys. Solids, 42, pages 1397-1434, 1994.

[10] K. W. Shahwan And A. M. WAAs, Non-self similar Decohesion along a Finite Interface of Unilaterally Constrained Delaminations. Proc. R. Soc. Lond. A., 153, 197, pages 515-550, 1997.

[11] M. Ortiz And A. Pandolfi, Finite-Deformation Irreversible Cohesive Elements for ThreeDimensional Crack-Propagation Analysis. Int. J. Numer. Meth. Eng., 44:1267-1282, 1999.

[12] S. Mohammadi, D.R.J. Orwen, and D. Peric, A Combined Finite/Discrete Element Algorithm for Delamination Analysis of Composites. Finite Element in Analysis and Design, 28(4), pages 321-336, 1998.

[13] C. G. Dávila, P. Camanho, And M.F.S.F. de Moura, Mixed-Mode Decohesion Elements for Analyses of Progressive Delamination. In Proceedings of the 42nd AIAA/ASME/ASCE/AHS/ASC Structures, Structural Dynamics and Materials Conference, Seattle, Washington, April 16-19, 2001.

[14] O. Allix and P. Ladevèze, Interlaminar Interface Modelling for the Prediction of Delamination. Composite Structures, 22, pages 235-242, 1992.

[15] Y. Mi, M. A. Crisfield, G.A.O. Davies, And H.-B. Hellweg, Progressive Delamination Using Interface Elements. Journal of Composite Materials, 32, pages 1246-1273, 1998.

[16] M. de Moura, J. A. Marques, And P. de Castro, Modeling Compression Failure after Low Velocity Impact on Laminated Composites using Interface Elements. Journal of Composite Materials, 31(15), pages $1462-1479,1997$.

[17] C. G. DÁvila And P. Camanho, Decohesion Elements using Two and Three-Parameter Mixed-Mode Criteria. In American Helicopter Society International Structures Specialists' Meeting, Williamsburg, VA, October 30-November 1, 2001.

[18] J. D. Whiтсомв, Analysis of Instability-Related Growth of a Through-Width Delamination. NASA TM 86301, 1984.

[19] E. M. Wu And R. C. Reuter JR., Crack Extension in Fibreglass Reinforced Plastics. Report No. 275, T \& AM, University of Illinois, 1965.

[20] J. R. REEDER, An Evaluation of Mixed-Mode Delamination Failure Criteria. NASA Technical Memorandum 104210, February 1992.

[21] G. BeER, An Isoparametric Joint/Interface Element for the Finite Element Analysis. Int. J. Numer. Methods Eng., 21, pages 585-600, 1985.

[22] René de Borst And J. G. Rots, Occurrence of Spurious Mechanisms in Computations of StrainSoftening Solids. Eng. Comput., 6, pages 272-280, 1989.

[23] J. Chen, M. A. Crisfield, A. J. Kinloch, E. P. Busso, F. L. Matthews, And Y. Qiu, Predicting Progressive Delamination of Composite Material Specimens Via Interface Elements. Mechanics of Composite Materials and Structures, 6, pages 301-317, 1999. 
TABLE 6.1

Graphite-Epoxy Properties

\begin{tabular}{cccccc}
\hline \hline$E_{11}$ & $E_{22}, E_{33}$ & $G_{12}, G_{13}$ & $G_{23}$ & $\nu_{12}, \nu_{13}$ & $\nu_{23}$ \\
\hline $150 \mathrm{GPa}$ & $11.0 \mathrm{GPa}$ & $6.0 \mathrm{GPa}$ & $3.7 \mathrm{GPa}$ & 0.25 & 0.45 \\
\hline \hline
\end{tabular}

TABLE 6.2

Interface Material Properties

\begin{tabular}{cccc}
\hline \hline$T_{2}^{c}, T_{3}^{c}$ & $T_{1}^{c}$ & $G_{I c}, G_{I I c}$ & $G_{I I I c}$ \\
\hline $10.5 \mathrm{ksi}$ & $9.0 \mathrm{Ksi}$ & $1.31 \mathrm{lb} / \mathrm{in}$. & $3.30 \mathrm{lb} / \mathrm{in}$. \\
\hline \hline
\end{tabular}

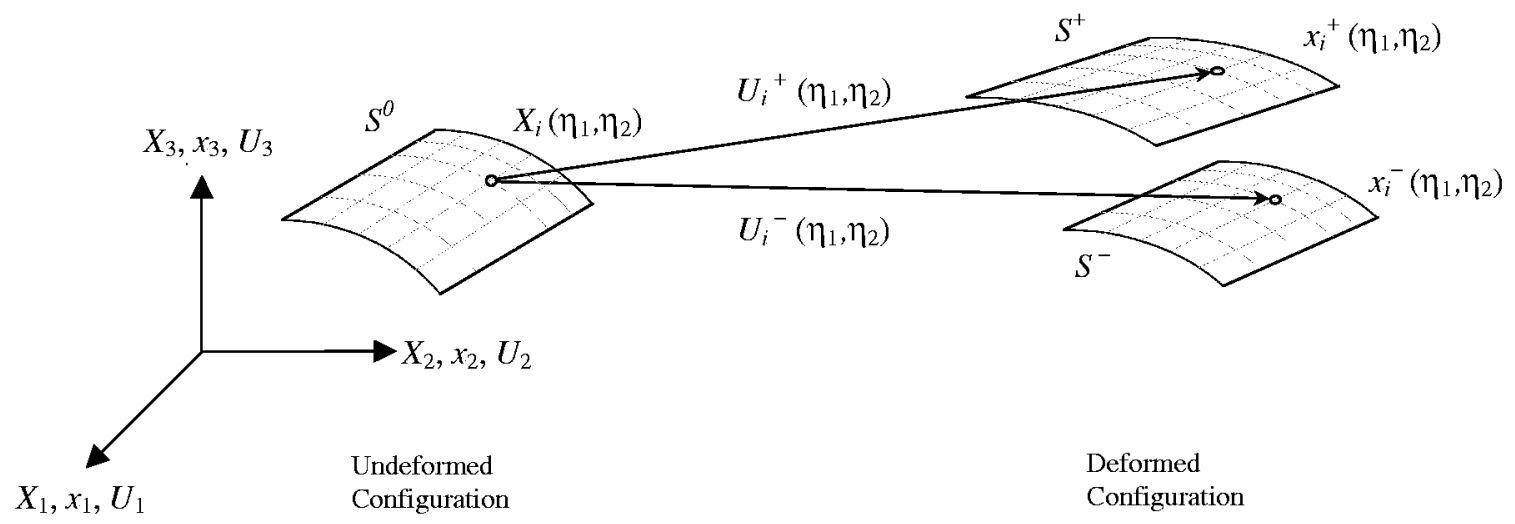

FIG. 6.1. Interface material deformation.

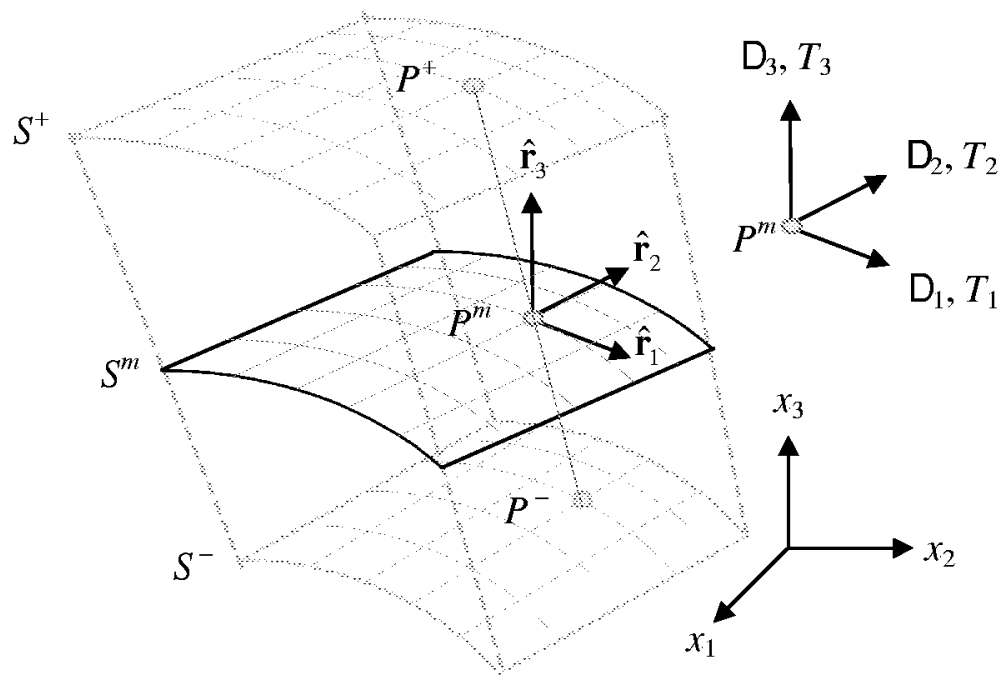

FIG. 6.2. Interface material mid-surface. 


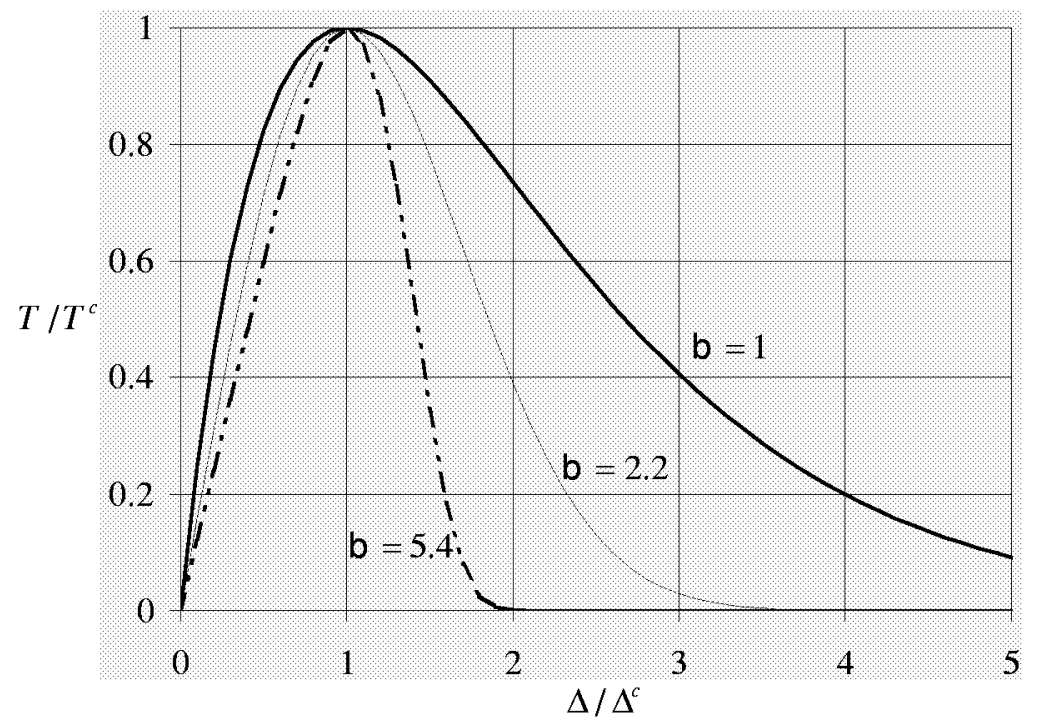

FiG. 6.3. Traction-stretching curve of spring as a function of $\beta$

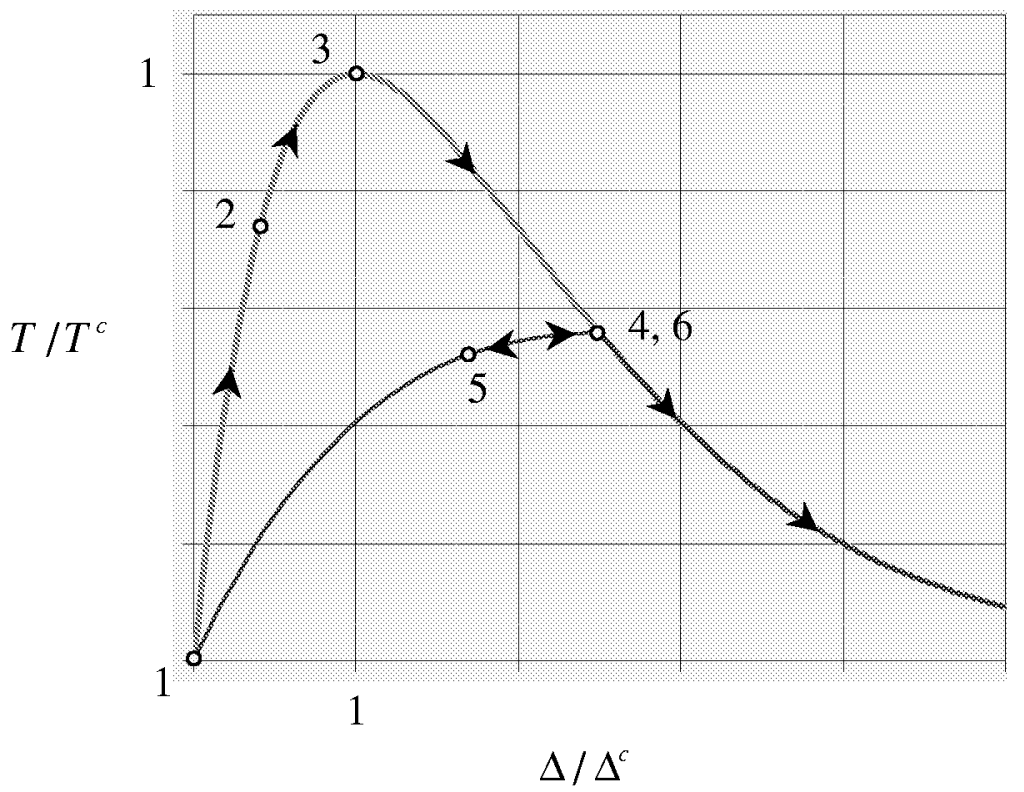

FIG. 6.4. Traction-stretching curve as a function of the evolution of damage of the spring with $\beta=1$ 


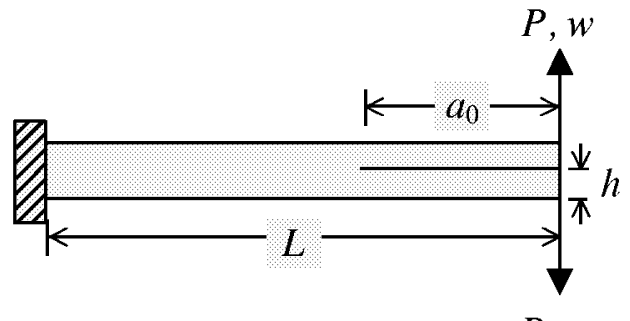

(a) Mode I- DCB

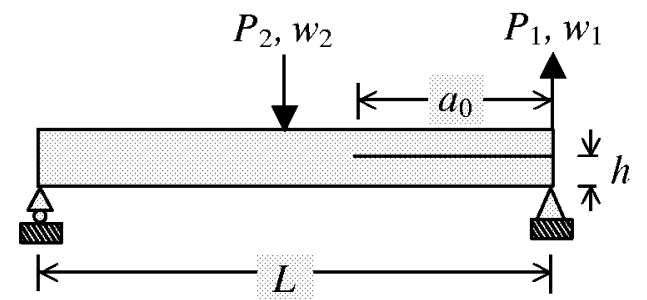

(c) Mode II - ENF, $P_{l}=0$

Mixed-Mode - MMB, $P_{1} \neq 0$

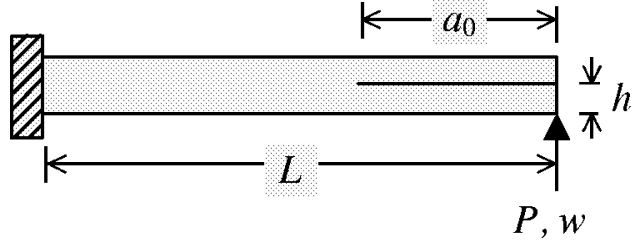

(b) Mode II - ELS

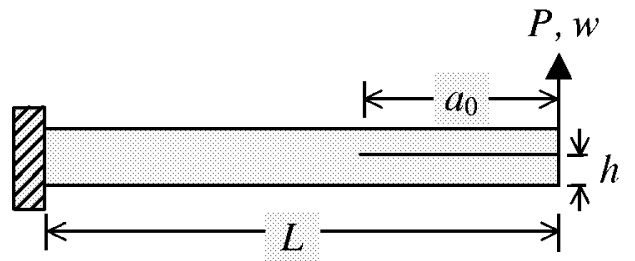

(d) Mixed-Mode - FRMM

FIG. 6.5. Fracture test specimen configurations.

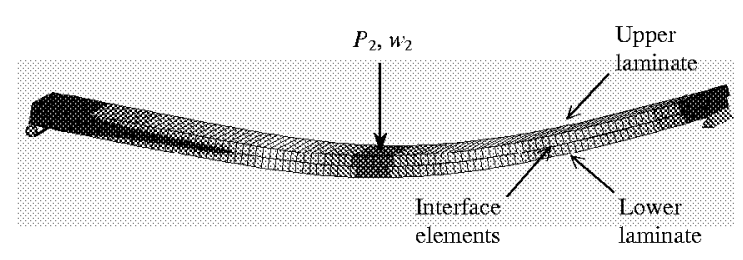

(a) Finite element model of the ENF

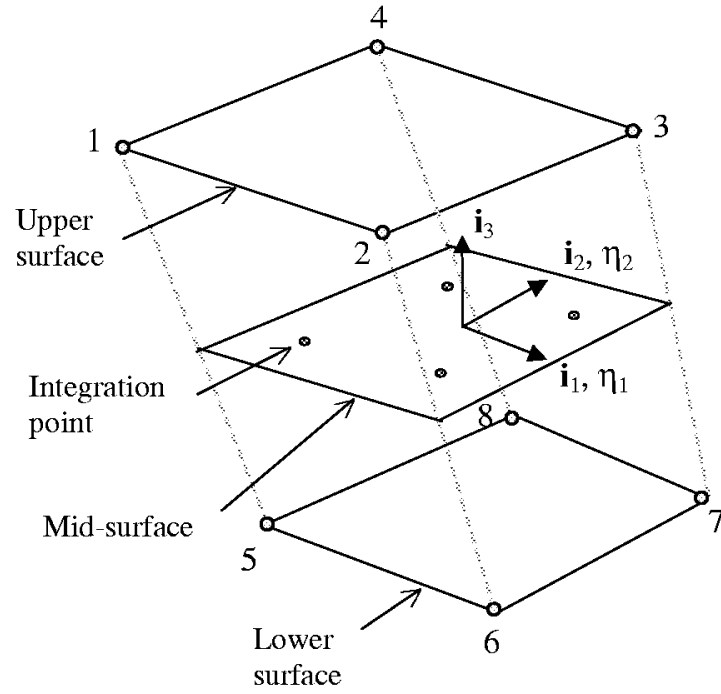

(b) Eight-node isoparametric interface element

FIG. 6.6. Finite element modeling. 


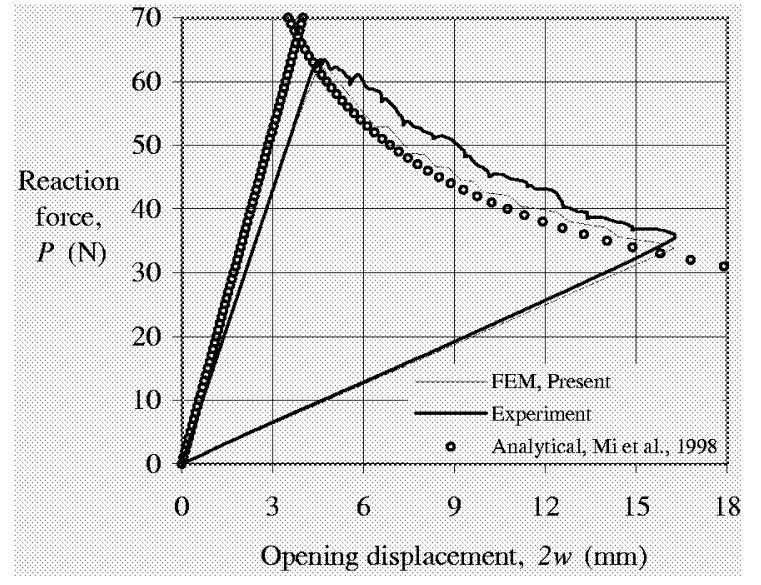

(a) Load-opening response of the DCB

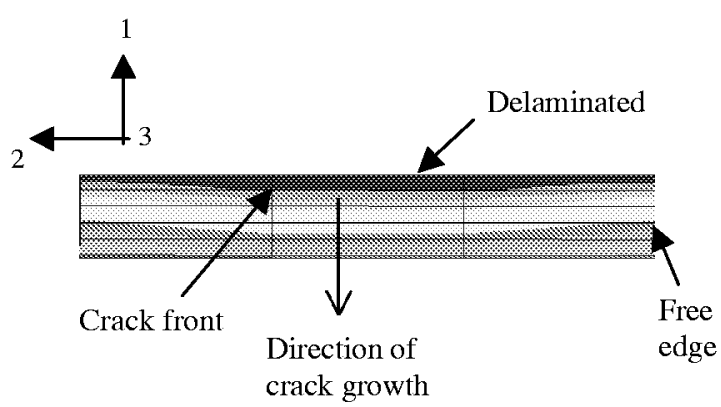

(b) Non-self similar delamination growth

FIG. 6.7. $D C B$ with $a_{0}=50 \mathrm{~mm}$

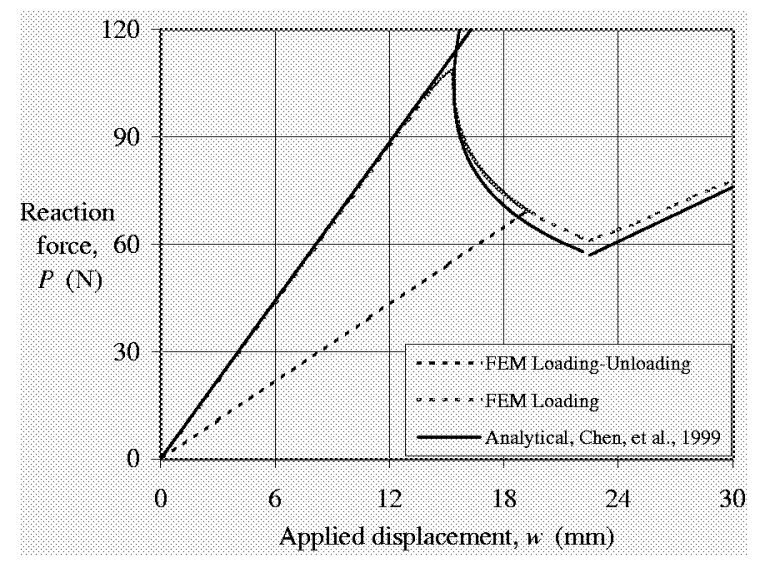

(a) ELS with $a_{0}=50 \mathrm{~mm}$

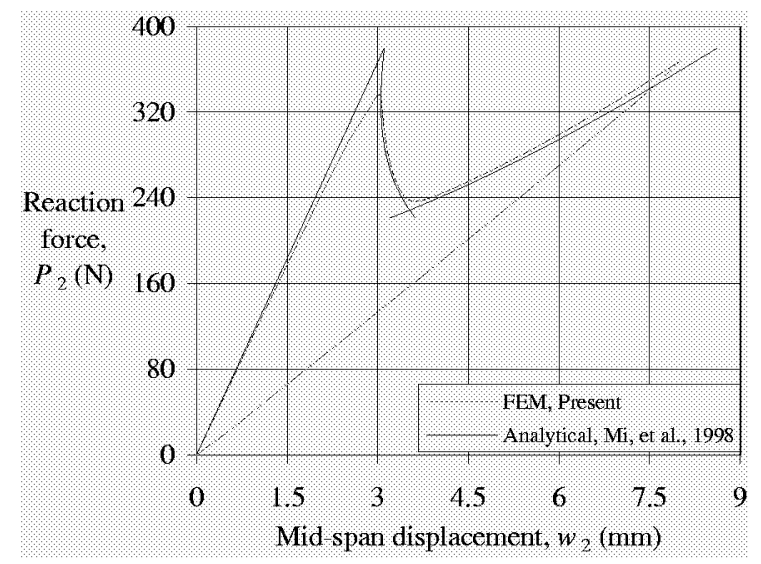

(b) ENF with $a_{0}=30$

FIG. 6.8. Load-displacement response of Mode II test specimen configurations. 


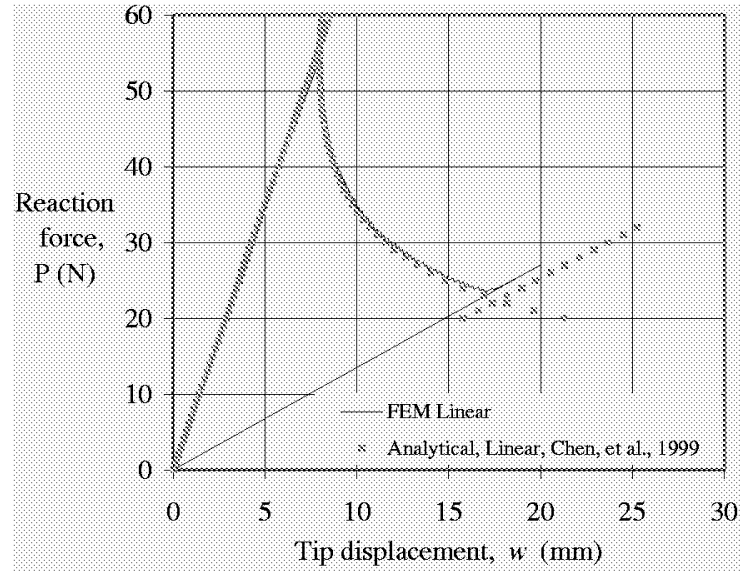

(a) FRMM with $\alpha=2$ and $a_{0}=40 \mathrm{~mm}$

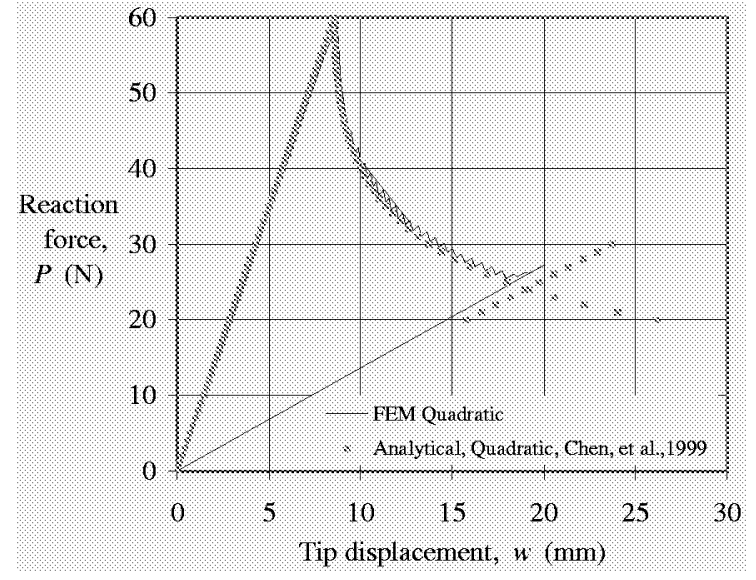

(b) FRMM with $\alpha=4$ and $a_{0}=40 \mathrm{~mm}$

FIG. 6.9. Load-displacement response of the FRMM test specimen configurations.

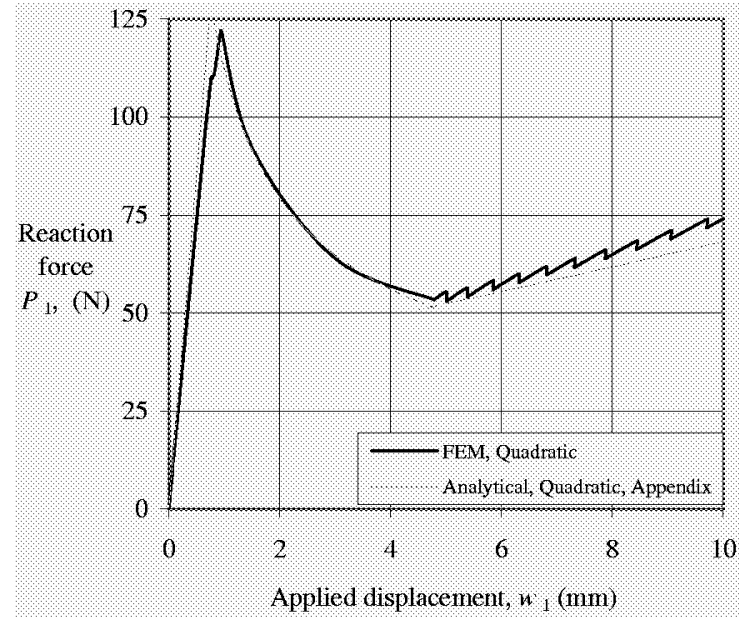

(a) MMB with $\alpha=4$ and $a_{0}=20 \mathrm{~mm}$

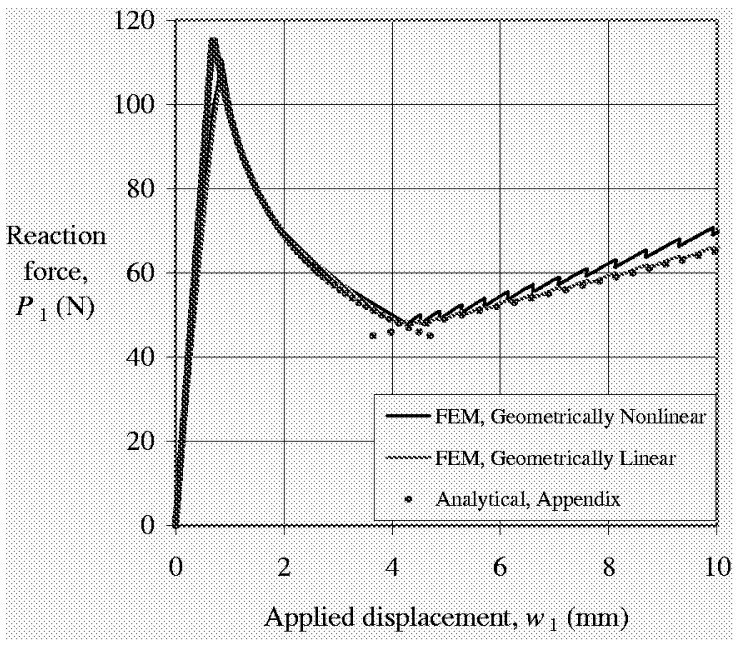

(b) MMB with $\alpha=2$ and $a_{0}=20 \mathrm{~mm}$

FIG. 6.10. Load-displacement response of the MMB test specimen configurations. 
Appendix A. Mixed-Mode Analytical Solutions. The beam analytical solutions based on linear elastic fracture mechanics for the MMB test specimen are presented without details. In general, the total energy release rate is

$$
G_{T}=G_{I}+G_{I I}
$$

$G_{I}$ and $G_{I I}$ are the Mode I and Mode II energy release rate contributions. The delamination propagates when,

$$
G_{T}=G_{C}=G_{I}^{m}+G_{I I}^{m}
$$

and $G_{c}$ is the critical energy release rate, $G_{I}^{m}$ and $G_{I I}^{m}$ are the the Mode I and Mode II energy release rates at crack propagation. For all the fracture test specimens, it is possible to express $\phi=G_{I}^{m} / G_{I I}^{m}$, where $\phi \in[0, \infty)$, so that the $G_{C}$ value can be computed based on the fracture criterion in Equation 2.2

$$
G_{c}=(1+\phi)\left(\left(\frac{\phi}{G_{I c}}\right)^{\alpha / 2}+\left(\frac{1}{G_{I I c}}\right)^{(\alpha / 2)}\right)^{-(2 / \alpha)}
$$

The derivations to obtain the expression of $\phi$ for the MMB specimen are omitted here, and is

$$
\phi=\frac{G_{I}}{G_{I I}}=\frac{G_{I}^{m}}{G_{I I}^{m}}=\frac{4}{3}\left(\frac{6 c-L}{2 c+L}\right)
$$

where $c$ is the length of the lever arm in the test fixture ([20]), and $L$ is the length of the MMB specimen. For simplifying purposes, the loads $P_{I}$ and $P_{I I}$ associated to modes I and II respectively are defined as

$$
P_{I}=\frac{L}{c}\left(\frac{6 c-L}{4 L}\right) P_{1}, \quad P_{I I}=\frac{L}{c}\left(\frac{2 c+L}{L}\right) P_{1}
$$

The load $P_{1}$ is defined in Figure 6.5c. The initial load-deflection response is linear and given by

$$
w_{1}=\frac{16 L}{3 c}\left(\frac{6 c-L}{4 L}\right) \frac{P_{1} a_{0}^{3}}{E I}
$$

where $\mathrm{E}$ is the Young's Modulus and $I$ is the moment of inertia. The load-deflection response, when delamination propagates with $a<L / 2$ is

$$
w_{1}=\frac{16 P_{I}}{3 E I}\left(\frac{8 B E I G_{C}}{64 P_{I}^{2}+3 P_{I I}^{2}}\right)^{3 / 2}
$$

where $B$ is the width of the beam. The load-displecement relation when delamination propagates with $a>L / 2$ is obtained by solving the quadratic equation for $a$,

$$
\begin{aligned}
& \left(64 P_{I}^{2}+3 P_{I I}^{2}-64 P_{I} P_{I I}\right) a^{2} \\
& -\left(6 P_{I I}^{2} L-32 P_{I} P_{I I} L\right) a+\left(3 P_{I I}^{2} L^{2}-8 B E I G_{C}\right)=0
\end{aligned}
$$

and substituting its solution into

$$
w_{1}=\frac{16 L}{3 c}\left(\frac{6 c-L}{4 L}\right) \frac{P_{1} a^{3}}{E I}
$$




\begin{tabular}{|c|c|c|c|}
\hline \multicolumn{3}{|c|}{ REPORT DOCUMENTATION PAGE } & $\begin{array}{l}\text { Form Approved } \\
\text { OMB No. 0704-0188 }\end{array}$ \\
\hline \multicolumn{4}{|c|}{ 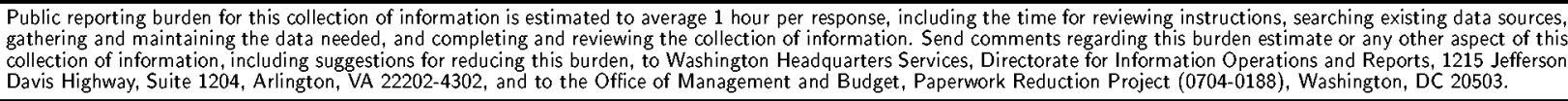 } \\
\hline 1. AGENCY USE ONLY(Leave blank) & $\begin{array}{l}\text { 2. REPORT DATE } \\
\text { August } 2002\end{array}$ & \multicolumn{2}{|c|}{$\begin{array}{l}\text { 3. REPORT TYPE AND DATES COVERED } \\
\text { Contractor Report }\end{array}$} \\
\hline \multicolumn{3}{|c|}{$\begin{array}{l}\text { 4. TITLE AND SUBTITLE } \\
\text { AN IRREVERSIBLE CONSTITUTIVE LAW FOR MODELING } \\
\text { THE DELAMINATION PROCESS USING INTERFACE ELEMENTS }\end{array}$} & \multirow[t]{2}{*}{$\begin{array}{l}\text { 5. FUNDING NUMBERS } \\
\text { C NAS1-97046 } \\
\text { WU } 505-90-52-01\end{array}$} \\
\hline \multicolumn{3}{|c|}{$\begin{array}{l}\text { 6. AUTHOR(S) } \\
\text { Vinay K. Goyal, Eric R. Johnson, Carlos G. Dávila, and Navin Jaunky }\end{array}$} & \\
\hline \multicolumn{2}{|c|}{$\begin{array}{l}\text { 7. PERFORMING ORGANIZATION NAME(S) AND ADDRESS(ES) } \\
\text { ICASE } \\
\text { Mail Stop } 132 \mathrm{C} \\
\text { NASA Langley Research Center } \\
\text { Hampton, VA } 23681-2199\end{array}$} & & $\begin{array}{l}\text { 8. PERFORMING ORGANIZATION } \\
\text { REPORT NUMBER } \\
\text { ICASE Report No. } 2002-25\end{array}$ \\
\hline \multicolumn{2}{|c|}{$\begin{array}{l}\text { 9. SPONSORING/MONITORING AGENCY NAME(S) AND ADDRESS(E } \\
\text { National Aeronautics and Space Administration } \\
\text { Langley Research Center } \\
\text { Hampton, VA 23681-2199 }\end{array}$} & $\begin{array}{l}\text { 10. SPONS } \\
\text { AGENC } \\
\text { NASA } \\
\text { ICASI }\end{array}$ & $\begin{array}{l}\text { 10. SPONSORING/MONITORING } \\
\text { AGENCY REPORT NUMBER } \\
\text { NASA/CR-2002-211758 } \\
\text { ICASE Report No. } 2002-25\end{array}$ \\
\hline \multicolumn{4}{|c|}{$\begin{array}{l}\text { 11. SUPPLEMENTARY NOTES } \\
\text { Langley Technical Monitor: Dennis M. Bushnell } \\
\text { Final Report } \\
\text { To be submitted to Composite Structures. }\end{array}$} \\
\hline \multicolumn{2}{|c|}{$\begin{array}{l}\text { 12a. DISTRIBUTION/AVAILABILITY STATEMENT } \\
\text { Unclassified-Unlimited } \\
\text { Subject Category } 34 \\
\text { Distribution: Nonstandard } \\
\text { Availability: NASA-CASI (301) } 621-0390\end{array}$} & & 12b. DISTRIBUTION CODE \\
\hline \multicolumn{4}{|c|}{$\begin{array}{l}\text { 13. ABSTRACT (Maximum } 200 \text { words) } \\
\text { An irreversible constitutive law is postulated for the formulation of interface elements to predict initiation and } \\
\text { progression of delamination in composite structures. An exponential function is used for the constitutive law such } \\
\text { that it satisfies a multi-axial stress criterion for the onset of delamination, and satisfies a mixed mode fracture criterion } \\
\text { for the progression of delamination. A damage parameter is included to prevent the restoration of the previous } \\
\text { cohesive state between the interfacial surfaces. To demonstrate the irreversibility capability of the constitutive law, } \\
\text { steady-state crack growth is simulated for quasi-static loading-unloading cycle of various fracture test specimens. }\end{array}$} \\
\hline \multirow{2}{*}{\multicolumn{3}{|c|}{$\begin{array}{l}\text { 14. SUBJECT TERMS } \\
\text { composite structures, progressive failure, ply damage mode, intradamage mode, } \\
\text { interlaminar damage mode, delamination, interface elements, decohesion elements, } \\
\text { buckling, postbuckling }\end{array}$}} & \begin{tabular}{|c} 
15. NUMBER OF PAGES \\
25 \\
\end{tabular} \\
\hline & & & $\begin{array}{c}\text { 16. PRICE CODE } \\
\text { A03 }\end{array}$ \\
\hline $\begin{array}{l}\text { 17. SECURITY CLASSIFICATION } \\
\text { OF REPORT } \\
\text { Unclassified }\end{array}$ & $\begin{array}{l}\text { 18. SECURITY CLASSIFICATION } \\
\text { OF THIS PAGE } \\
\text { Unclassified }\end{array}$ & $\begin{array}{l}\text { 19. SECURITY CLASSIFICATION } \\
\text { OF ABSTRACT }\end{array}$ & $\begin{array}{l}\text { 20. LIMITATION } \\
\text { OF ABSTRACT }\end{array}$ \\
\hline NSN 7540-01-280-5500 & & & $\begin{array}{l}\text { Standard Form 298(Rev. 2-89) } \\
\text { Prescribed by ANSI Std. Z39-18 } \\
\text { 298-102 }\end{array}$ \\
\hline
\end{tabular}

